\title{
THE CAUSE OF HYPERCALCURIA IN SARCOID AND ITS TREATMENT WITH CORTISONE AND SODIUM PHYTATE ${ }^{1,2}$
}

\author{
By PHILIP H. HENNEMAN, ELEANOR F. DEMPSEY, EVELYN L. CARROLL, AND \\ FULLER ALBRIGHT
}

\author{
(From the Medical Service of the Massachusetts General Hospital and the Department of \\ Medicine, Harvard Medical School, Boston, Mass.)
}

(Submitted for publication March 8, 1956; accepted July 25, 1956)

Sarcoid is a chronic granulomatous disease of unknown etiology which may involve any or all organ systems (1). Harrell and Fisher (2) in 1939 first called attention to an elevated serum calcium in 6 of 11 patients with sarcoid. Other abnormalities noted were hyperproteinemia, due to hyperglobulinemia, and elevated serum alkaline phosphatase. The blood inorganic phosphorus was not decreased, a major point in the differential diagnosis with hyperparathyroidism. The urinary calcium excretion was not reported but we now know that hypercalcuria is common in sar$\operatorname{coid}^{3}$ and often the cause of renal stones which are usually composed of calcium oxalate.

The cause of hypercalcemia and hypercalcuria in sarcoid has been obscure. Schaumann (4) demonstrated sarcoid involvement of bone and indicated that this is found more commonly histologically than radiologically. Small "punched out" areas of bone destruction may be found in 15 to 29 per cent of patients (1), particularly in the phalanges but rarely in the long bones and skull as well. Even generalized bone demineralization has been reported (5) but most patients with sarcoid, including those patients with hypercalcuria of many years' duration, have minimal or no detectable bone disease. The common concurrence of skin involvement with bone involvement has been emphasized (1).

1 These studies were supported in part by grants from the American Cancer Society on recommendation of the Committee on Growth of the National Research Council, the United States Public Health Service, and the Rockefeller Foundation and were carried out in the Mallinckrodt Research Ward of the Massachusetts General Hospital.

2 Presented in part before the American Society for Clinical Investigation, May, 1954.

3 Dr. John Eager Howard (3) (Johns Hopkins Hospital) estimates that 20 to 30 per cent of patients with sarcoid present hypercalcemia.
It has been suspected that the hyperglobulinemia in sarcoid might "bind" an excessive amount of calcium and thus account for hypercalcemia. If this extra moiety of calcium were bound and unionized it probably would not pass the glomerular filter and produce hypercalcuria. It is of interest that berylliosis, which may produce a clinical and pathological picture almost indistinguishable from sarcoid, also may be associated with hypercalcuria. ${ }^{4}$

Evidence is presented in this paper that the hypercalcuria in sarcoid is not due to bone destruction, but is due to a disturbed metabolic pattern closely resembling that of vitamin $\mathrm{D}$ overdosage.

\section{METHODS}

The data presented are derived from four complete balance studies; the analytical methods previously described (7) were used except that sodium and potassium were determined with a lithium internal standard flame photometer (8), magnesium by the Briggs' method (9), and urinary 17-ketosteroids by the micro method of Per Vestergaard (10). A single constant diet was used throughout each study rather than 3 alternating diets as previously described. Fasting blood samples were used for all studies.

\section{CASE HISTORIES}

In view of the highly variable clinical picture of sarcoid the case histories of our 3 patients are presented in some detail.

\section{Case 1, A. M., M. G. H. No. 252484}

This 37-year-old Lithuanian-born Jewish housewife was first seen in 1940 because of chronic cough of 2 years' duration. Positive findings on examination were cyanosis, mild generalized lymphadenopathy and splenomegaly. The lungs were extensively involved with nodular densities by $x$-ray. Tuberculin skin tests and guinea-pig inoculations of sputum were negative, as is the rule in

4 Dr. Harriet L. Hardy (6) (Massachusetts General Hospital) reports a 20 per cent incidence of kidney stones in berylliosis patients studied prior to 1952. 
sarcoid. A lymph node biopsy was interpreted as consistent with sarcoid.

In 1941 the patient complained of right flank pain and a renal stone was demonstrated by $x$-ray. Hypercalcemia and hypercalcuria were demonstrated. For two months prior to the balance study (vide infra) the patient received three Haliver Oil capsules daily (total 300 units vitamin $\mathrm{D}$ ).

The patient's serum calcium gradually returned to normal and remained normal after 1943 despite increasing hyperglobulinemia and pulmonary insufficiency. A renal stone was removed in 1948 and was found to contain primarily calcium oxalate with some calcium phosphate.

The patient died of cor pulmonale and pulmonary infarction in 1954.

\section{Case 2, M. S., M.G.H. No. 793791}

This 38-year-old Russian-born machinist first noted polyuria, polydipsia, pruritus, weight loss, and a scalp infection in March, 1952. Mild diabetes mellitus was diagnosed but diet and insulin therapy did not diminish his polydipsia. In June, 1952, he began to note photophobia, halos about lights and progressive blurring of vision. In November, 1952, he came to the Massachusetts Eye and Ear Infirmary where Dr. David Cogan found a curious granular superficial opacity just beneath the epithelium occupying practically the entire cornea of each eye but separated from both the upper and lower limbus by a 1 to $2 \mathrm{~mm}$. clear zone. The uveal tract appeared normal. Because of the finding of hypercalcemia he was referred to us for study.

In addition to the eye findings there was fever, minimal brown pigmentation of the skin, and mild hepatosplenomegaly. The lungs were clear to physical examination and revealed by x-ray only a well healed calcified primary tuberculous complex in the right upper lung. The bones were normal. The tuberculin skin test (1:100) was negative. A liver aspiration biopsy revealed multiple granulomata with Langhans type giant cells but no evidence of caseation, findings consistent with a diagnosis of sarcoid. Biopsy of the corneal epithelium showed a positive von Kossa stain for calcium.

Since there was no known occupational exposure to beryllium, diagnoses of sarcoid and diabetes mellitus were made and the patient was transferred to the metabolic ward. For several months prior to study the patient had taken daily 1 capsule Vi-Syneral and 2 capsules Lederplex (8). The former is advertised to contain 1,000 units vitamin $\mathrm{D}$.

Following 21 months' continuous therapy with oral cortisone and 6 months' therapy with sodium phytate, the patient's corneae almost entirely cleared and his vision sufficiently improved for him to return to his original occupation as a wire-extruder. Cortisone was discontinued in January, 1955; hypercalcemia returned abruptly in June, 1955. Combined therapy with cortisone and sodium phytate have diminished his hypercalcemia but failed to decrease his urinary calcium excretion below $400 \mathrm{mg}$. daily in the succeeding year.

\section{Case 3, M. L., M.G.H. No. 445378}

This 38-year-old Jewish fuel-oil salesman was born in Massachusetts and was well until 1944 when diffuse pulmonary fibrosis was discovered accidentally by $x$-ray examination. Tuberculosis was rendered unlikely by negative sputum examinations and negative tuberculin skin tests. Renal colic first occurred in 1946. The left kidney was removed because of nephrolithiasis and pyelonephritis in 1953. Granulomata consistent with sarcoid were found in a lymph node biopsy in 1951 . Because of the recurrent nephrolithiasis (calcium oxalate) in the sole remaining kidney and B. Pyocyaneus pyelonephritis resistant to all antibiotics he was referred to us in December, 1953, by Dr. Melvin Lyons of Boston. The only history of vitamin $D$ ingestion was of about 1,000 units daily ( 1 Theragran capsule) for 30 days six months prior to study.

Positive physical findings were brown pigmentation of the face, slight generalized lymphadenopathy and an enlarged right kidney. The lung findings by $x$-ray were consistent with extensive fibrosis. A single renal stone was noted by $x$-ray initially but the patient subsequently passed small stones weekly and even more frequently at times.

Following completion of the balance study the patient was maintained on daily sodium phytate therapy for 13 months, during which time his urinary calcium excretion was 30 to $90 \mathrm{mg}$. per 24 hours; he was stone-free and urine cultures were negative. Four months after discontinuing phytate therapy (in July, 1955) hypercalcemia returned; normal serum and urinary calcium excretion have again been maintained for the past 12 months with prednisone 5 therapy. In June, 1956, the patient developed a tumor of the right breast which was proved by excision to be benign gynecomastia.

\section{RESULTS}

\section{Study 1. Patient A. M. (Figure 1)}

This 36-day balance study is divided into 18 days on a very low calcium intake and 18 days on a medium calcium intake; the latter was achieved by the addition of 5 grams of calcium gluconate to the low calcium diet.

On the low calcium (estimated $60 \mathrm{mg}$.) constant intake the urinary calcium averaged $407 \mathrm{mg}$. and the fecal calcium averaged $23 \mathrm{mg}$., which gave a negative calcium balance of $370 \mathrm{mg}$. per day. On the moderate calcium intake of $560 \mathrm{mg}$. per day the urinary calcium averaged $456 \mathrm{mg}$., the fecal calcium $138 \mathrm{mg}$. and the negative calcium balance only $34 \mathrm{mg}$. per day. The patient was in nitrogen balance but in slightly negative phosphorus and calcium balance throughout the study. The serum

\footnotetext{
5 Prednisone was generously supplied by Schering Corporation.
} 
calcium was elevated and the serum phosphorus and serum alkaline phosphatase were normal. The fecal phosphorus was low throughout the study.

The observation that the calcium balance varied with the calcium intake was interpreted in 1941 (11) as favoring a metabolic cause for the hypercalcuria and hypercalcemia of sarcoid since varying the calcium intake would have had less effect on the calcium balance if bone destruction were the cause of the hypercalcuria. Unnoticed in 1941, but of greater significance, was the extremely low fecal calcium excretion. This suggests that one

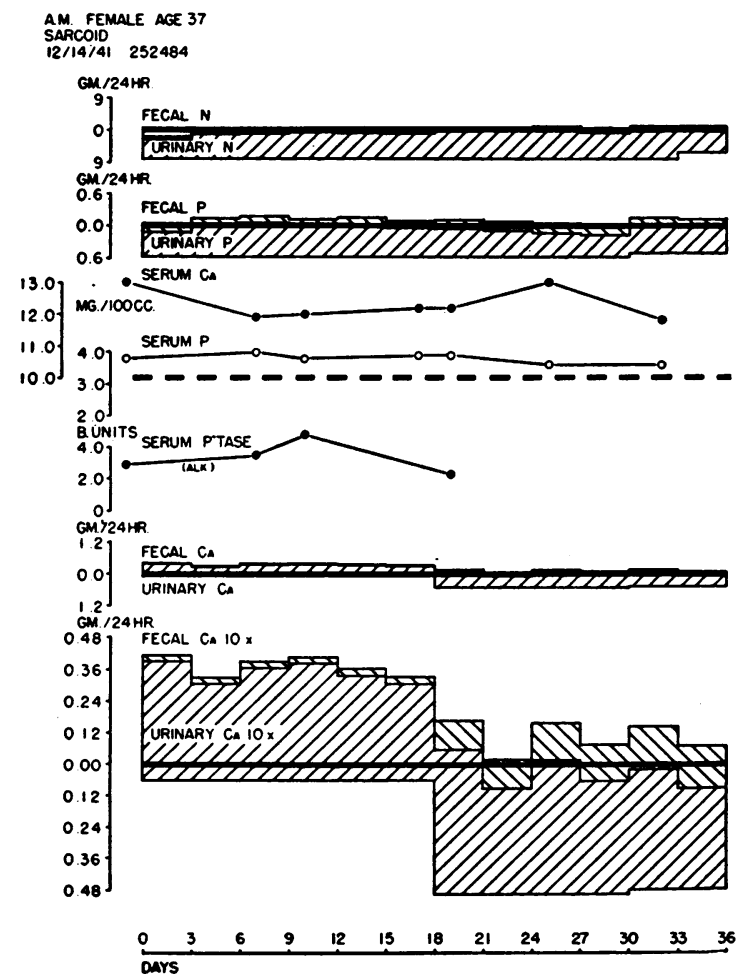

Fig. 1. Study 1, The Nitrogen, Phosphorus and Calcium Balance Data during Low and Moderate Calcium Intakes of A. M.

In each balance figure the intake is measured down from the heavy zero baseline. The urinary and fecal excretion are charted up from the intake line. Negative balance is shown by a hatched area above the zero baseline and positive balance by a clear area below the zero baseline.

The relative scales for nitrogen, phosphorus, calcium and potassium represent the ratios of these substances in protoplasm and bone. The scales for sodium, chloride and magnesium were chosen arbitrarily.

The dietary intakes in this study were calculated from dietary tables; diets in the other studies were analyzed. The fecal nitrogen was estimated to be 10 per cent of intake; fecal calcium and phosphorus were measured.

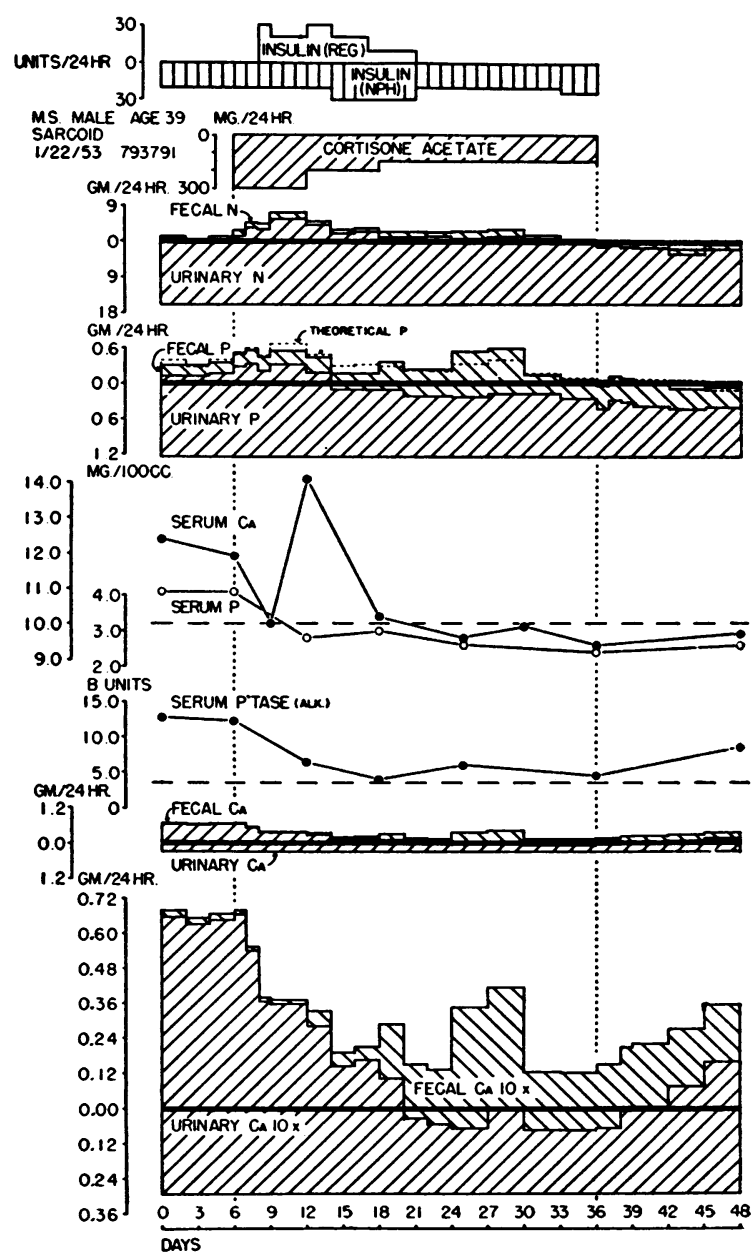

Fig. 2. Study 2, The Nitrogen, Phosphorus, and Calcium Balance Data during Cortisone Therapy of M. S., a 39-Year-Old Man with Sarcoid

The calcium data are recharted below for clarity on a $10 \times$ larger scale.

The "theoretical " phosphorus balance is charted as a broken line on the "actual" phosphorus balance.

cause for the hypercalcuria may be increased absorption of calcium from, or decreased excretion into, the intestinal tract.

\section{Study 2. Patient M. S. (Figures 2, 3, and 4)}

This 48-day balance study consists of 6 days fore-control, 6 days on $300 \mathrm{mg}$. oral cortisone acetate ${ }^{6}$ daily in divided doses, 6 days on $200 \mathrm{mg}$. cortisone, 18 days on $150 \mathrm{mg}$. cortisone and 12 days after-control off cortisone. NPH insulin, usually 20 units, was given daily and regular in-

${ }^{6}$ Cortisone acetate was generously supplied by Merck \& Co. 
sulin added according to the degree of glycosuria. An episode of hypoglycemia, the first day off cortisone, led to discontinuance of insulin for the remainder of the study.

The most important changes concern calcium and phosphorus metabolism. Note in Figure 2 that the hypercalcemia and hyperphosphatemia disappeared on cortisone therapy. Note further that during the fore-control period when on a calcium intake of $292 \mathrm{mg}$. per day the patient's uri-

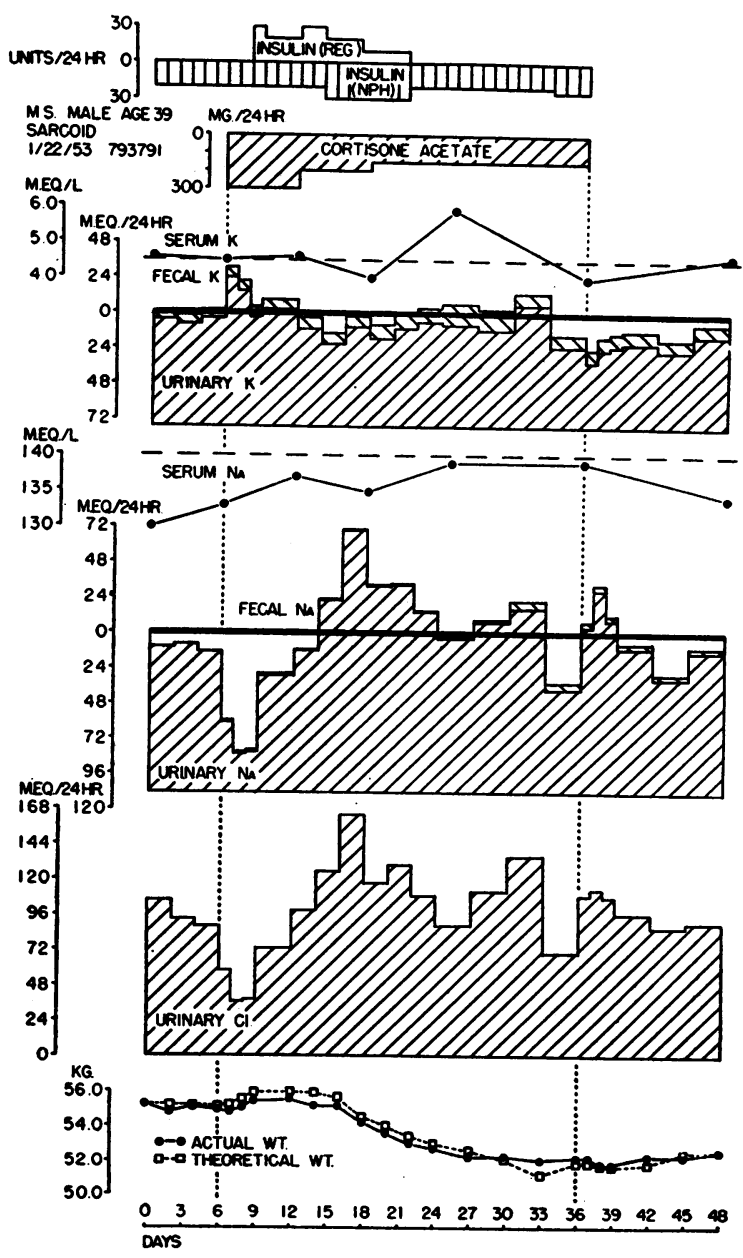

Fig. 3. The Potassium, Sodium and Chloride Balance Data, Actual and Theoretical Weights in STUDY 2

Only urinary chloride is charted since fecal and dietary chloride were not measured.

The theoretical weight is that calculated from changes in nitrogen, potassium and sodium balances.

The urinary potassium increased abruptly the first two days on cortisone; the urinary potassium: nitrogen ratio exceeded the usual $(2.7: 1)$ protoplasmic ratio of these substances during these two days.

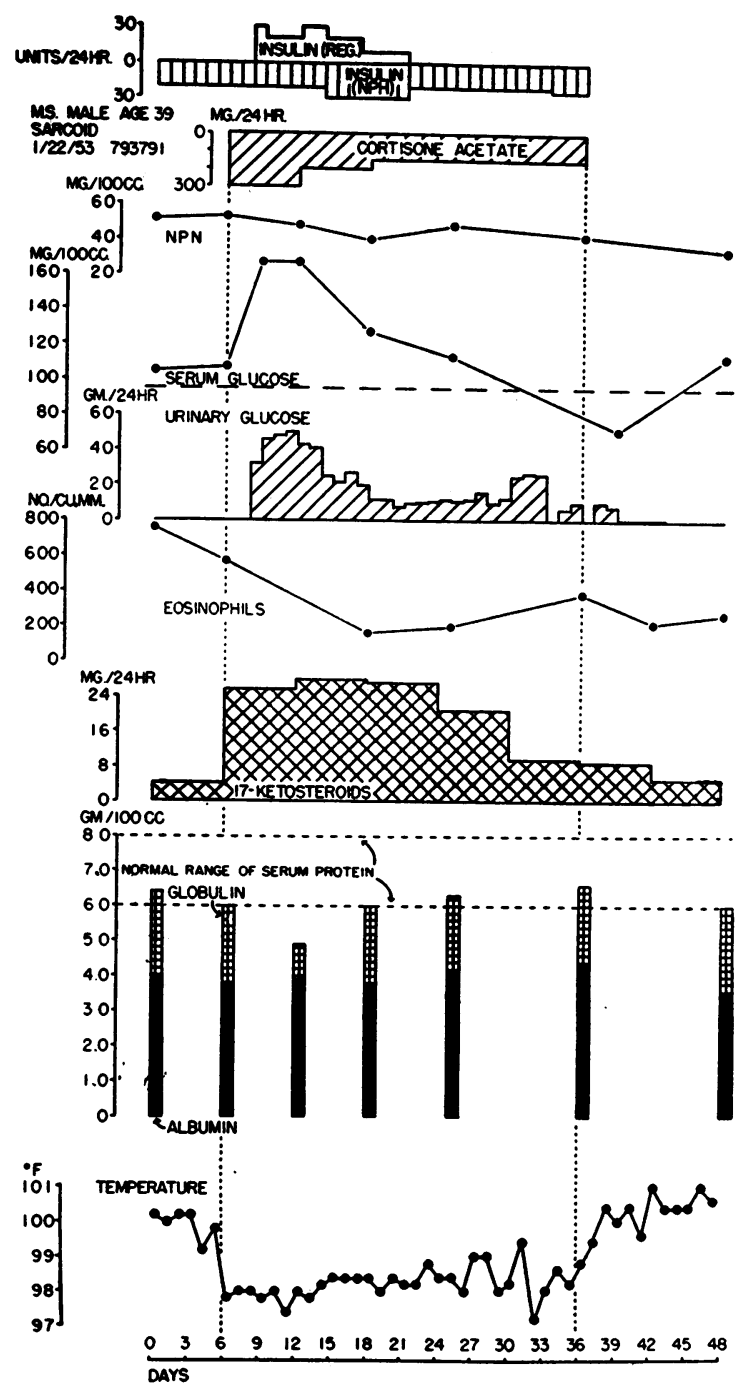

Fig. 4. Further Data of Study 2

The serum NPN fell to normal levels on cortisone. Glycosuria was absent prior to and after cortisone administration, but was as high as $45 \mathrm{Gm}$. per day on the largest doses of cortisone. The rise in 17-ketosteroid excretion may represent excretion of cortisone metabolites and improvement in liver function (12). Evidence for the latter was the observed diminution in size of the liver and spleen and the fall in serum alkaline phosphatase to normal values during cortisone administration. The 4:00 P.M. daily oral temperatures fell to normal on the larger doses of cortisone, rose slightly when the cortisone dosage was reduced, and returned to fore-control levels on discontinuing cortisone; this finding suggested that the sarcoid process was still active at the end of the study. The serum proteins were normal, as determined by the Howe (13) method and showed no consistent changes ${ }^{7}$ during cortisone therapy.

${ }^{7}$ Electrophoresis (courtesy of Dr. Karl Schmid) of the serum proteins gave the following results: 


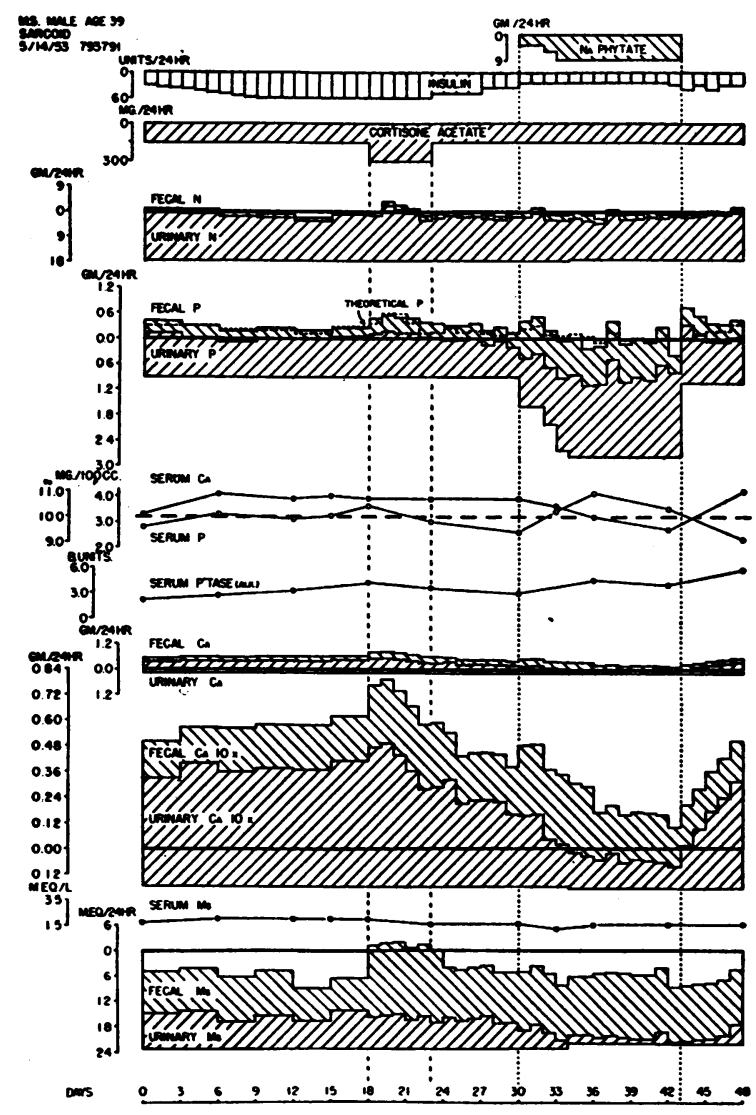

Fig. 5. Study 3, The Nitrogen, Phosphorus, Calcium and Magnesium Balance Data during Cortisone and Sodium Phytate Treatment of $M$. S.

Note that $150 \mathrm{mg}$. cortisone daily failed to return the serum and urinary calcium to normal levels. Note also that on this dose of cortisone the fecal calcium was at normal levels.

Ten units crystalline insulin were given days 1 to 22 , 43 and 45 plus protamine zinc insulin to total amount charted.

\section{TABLE I}

Results of serum protein electrophoresis on M.S.

\begin{tabular}{lcrrrrrr}
\hline & & \multicolumn{6}{c}{ Globulins } \\
\cline { 3 - 7 } & Albumin & $\alpha_{1}$ & $\alpha_{2}$ & $\beta_{1}$ & $\beta_{2}$ & $\gamma$ \\
\hline Normal values & 55 & 5 & 9 & 13 & 7 & 11 & $\%$ \\
M.S. pre-cortisone & 52 & 6 & 18 & 7 & 6 & 11 & $\%$ \\
M.S. post-cortisone & 60 & 2 & 12 & 10 & 6 & 10 & $\%$
\end{tabular}

Dr. Milton B. Engel (University of Illinois) reported the patient's serum mucoproteins to be increased (41 $\mathrm{mg}$. per cent carbohydrate residue, $5 \mathrm{mg}$. per cent tyrosine residue) before cortisone and little changed (38.3 $\mathrm{mg}$. per cent carbohydrate residue, $4.9 \mathrm{mg}$. per cent tyrosine residue) after cortisone. He reports the normal value of the carbohydrate residue to be about $16 \mathrm{mg}$. per cent. nary calcium averaged $930 \mathrm{mg}$. per day and the fecal calcium averaged only $23 \mathrm{mg}$. per day. The administration of cortisone produced a rapid steplike reduction in urinary calcium to a minimum value of $216 \mathrm{mg}$. per day, an increase in fecal calcium to $417 \mathrm{mg}$. per day, and a decrease in the negativity of the calcium balance. The urinary calcium rose again on discontinuing cortisone.

Note that the fecal phosphorus was low during the fore-control and increased when the fecal calcium increased during cortisone therapy. The "theoretical" phosphorus balance (7), i.e., that explained by the nitrogen and calcium balances, is charted in the actual phosphorus balance in Figure 2 as a broken line. It agrees well with the actual phosphorus balance.

\section{Study 3. Patient M.S. (Figures 5, 6, and 7)}

M. S. was discharged from the hospital on 150 mg. cortisone daily. At home he continued to manifest slight hypercalcemia and marked hypercalcuria which averaged about $500 \mathrm{mg}$. per day. This latter value is to be contrasted with the minimum urinary calcium of $216 \mathrm{mg}$. per day noted on

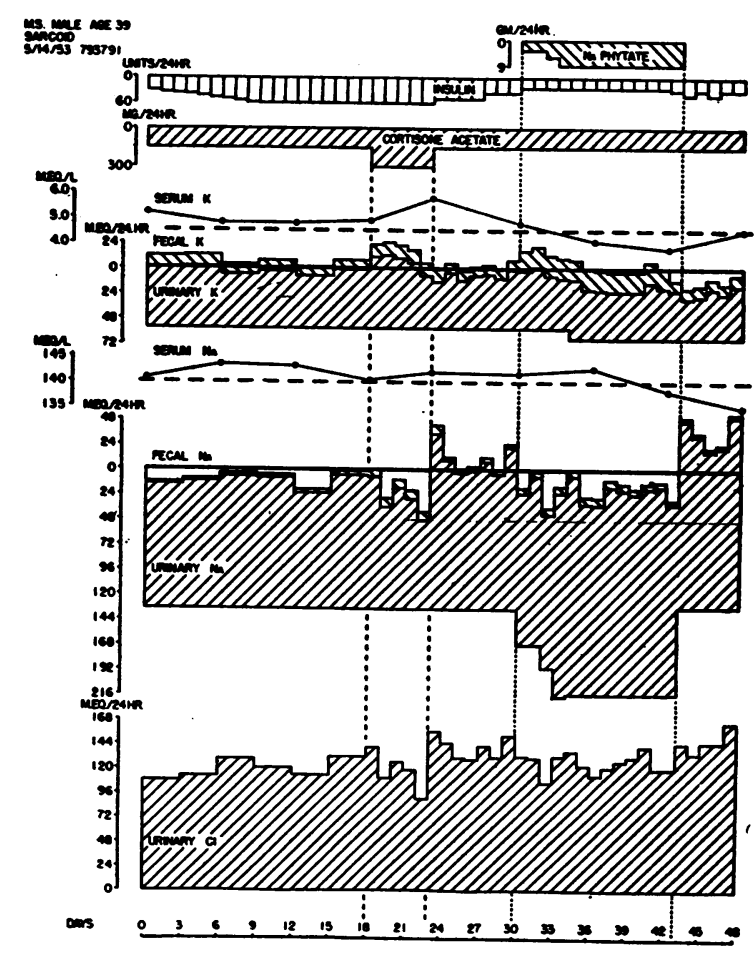

Fig. 6. Potassium, Sodium and Chloride Balance Data during Study 3 


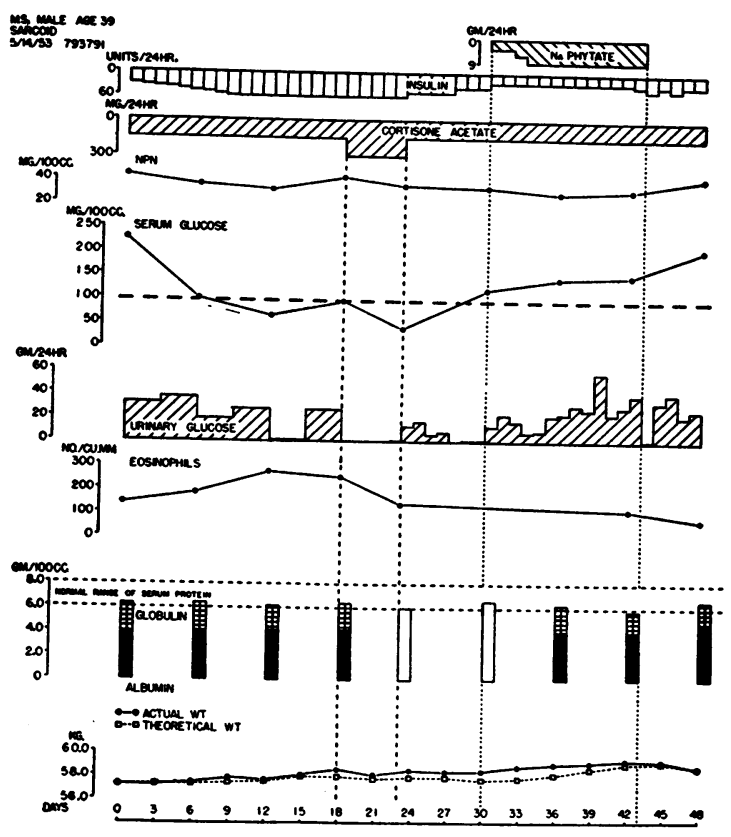

Fig. 7. Further Data of Study 3

The open serum protein columns indicate that total protein only was determined.

the same dose of cortisone during the balance study. Three possible reasons for this higher urinary calcium come to mind:1) the intensity of the underlying sarcoid process might have increased; if this were so larger doses of cortisone might lower his urinary calcium; 2) this hypercalcuria might reflect an anti-anabolic effect of cortisone on the bones; larger doses of cortisone would be expected to intensify this effect; and 3) a higher calcium intake at home might be responsible for the higher urinary calcium excretion. Therefore a second study was begun to test the effect of calcium intake and size of cortisone dose. Investigated also was the effect of sodium phytate, a substance reported (14) to increase fecal calcium excretion.

This 48-day complete balance study includes 18 days fore-control on $150 \mathrm{mg}$. cortisone daily, 5 days on $300 \mathrm{mg}$. cortisone daily, 7 days on 150 mg. cortisone daily, 13 days on sodium phytate ${ }^{8}$

\footnotetext{
8 Sodium phytate (Inositol Hexaphosphate) was supplied on request as a dry powder by E. R. Weidlein, Jr., Corn Products Refining Company, New York, and is now distributed by Dr. Douglas B. Remsen, The Squibb Institute, New Brunswick, New Jersey. A 15 per cent solution in distilled water had a pH of 7.2. By assay each $100 \mathrm{Gm}$. sodium phytate powder contained $970 \mathrm{mEq}$. sodium, 3.88
}

3.6 to $9.0 \mathrm{Gm}$. per day, and 5 days post-control. Insulin was administered according to the degree of glycosuria.

Greatest interest attaches to the calcium, phosphorus, and magnesium balances. On $150 \mathrm{mg}$. cortisone daily the serum calcium was slightly elevated, the serum phosphorus and the serum magnesium both remaining normal. On a constant calcium intake of $178 \mathrm{mg}$. the urinary calcium excretion of the fore-control averaged 551 mg. per day and the fecal calcium $193 \mathrm{mg}$. per day. The patient was in moderately positive magnesium balance.

When the cortisone dose was increased to 300 $\mathrm{mg}$. per day for 5 days there was a small nitrogen diuresis, a temporary increase in urinary calcium and phosphorus excretions, and finally a step-like decrease in urinary calcium which was still continuing through the 13 days of phytate administration. Stool calcium was increased very slightly during and immediately after the larger dose of cortisone. The serum calcium level did not change perceptibly but the serum phosphorus decreased during and after the larger doses of cortisone. The larger dose of cortisone produced an unsus-

$\mathrm{Gm}$. inorganic phosphorus, $21.2 \mathrm{Gm}$. total phosphorus, and $4.8 \mathrm{Gm}$. unaccounted for which is probably water. By inorganic phosphorus is meant that amount reacting in the Fiske and Subbarow method (15) before ashing; by total phosphorus is meant that amount reacting in the Fiske and Subbarow method after wet ashing of the specimen. The difference ( 82 per cent) is assumed to represent phosphorus organically bound in the phytate molecule.

The theoretical formula for Phytic Acid is as follows (16):

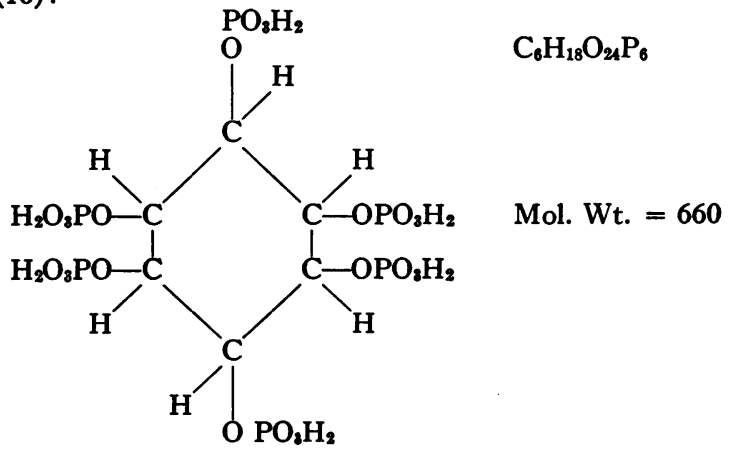

Assuming that the analyzed $3.88 \mathrm{Gm}$. inorganic phosphorus is a neutral mixture of $\mathrm{Na}_{2} \mathrm{HPO}_{4}$ and $\mathrm{NaH}_{2} \mathrm{PO}_{4}$ contaminating the current sodium phytate preparation, the above analysis indicates approximately $8 \mathrm{mEq}$. Na per $\mathrm{mM}$ phytic acid at $\mathrm{pH} 7.2$ and a molecular weight of sodium phytate of 836 . The exact physical-chemical state of sodium phytate is not known. 
tained increase in fecal magnesium but no change in urinary magnesium.

When sodium phytate, $3.6 \mathrm{Gm}$. per day for 2 days, then $9.0 \mathrm{Gm}$. per day was administered for 11 days there was a continued fall in urinary calcium to a low value of $120 \mathrm{mg}$. per day. That this further fall in urinary calcium was due to sodium phytate and not to the previous period on $300 \mathrm{mg}$. cortisone daily is supported by the observation that on discontinuing sodium phytate the urinary calcium rapidly rose to $502 \mathrm{mg}$. per day. The fecal calcium increased approximately $100 \mathrm{mg}$. per day the first 6 days on sodium phytate, was unchanged the remaining 7 days on sodium phytate, and was slightly less during the 5 days off sodium phytate. The calcium balance was less negative on sodium phytate. The serum calcium fell to normal and the serum phosphorus rose during sodium phytate; these changes were reversed when sodium phytate was discontinued.

On sodium phytate the total phosphorus intake increased 1,873 mg. per day; the fecal phosphorus increased $500 \mathrm{mg}$. and the urinary phosphorus increased approximately $1,000 \mathrm{mg}$. per day to account for a gain of $300 \mathrm{mg}$. per day in phosphorus balance.

The fecal magnesium increased approximately $4 \mathrm{mEq}$. and the urinary magnesium decreased approximately $5 \mathrm{mEq}$. on sodium phytate.

In regard to the three possible reasons why M. S.'s urinary calcium was higher at home on $150 \mathrm{mg}$. cortisone than it had been during the first study on the same dose of cortisone, one can conclude that this dose of cortisone had corrected the excessive calcium absorption but had only partially corrected the high urinary calcium excretion. The high urinary calcium was not due to the higher calcium intake at home since the urinary calcium did not decrease on a very low calcium intake in this second study. The hypercalcuria did not reflect an anti-anabolic effect of cortisone on the bones since increasing the cortisone dosage decreased rather than increased the urinary calcium. Thus it seems that either the severity of the sarcoid and its associated abnormality in calcium metabolism had increased or larger doses of cortisone were required to suppress sarcoid than to maintain this suppression. Indeed when cortisone therapy was reinstituted after the first study there was no preliminary period on larger doses.
In this study sodium phytate decreased the urinary calcium but did not increase the fecal calcium. The decrease in urinary calcium may have been due to increased phosphorus intake (see below). Sodium phytate did decrease urinary magnesium by approximately the same amount it increased fecal magnesium.

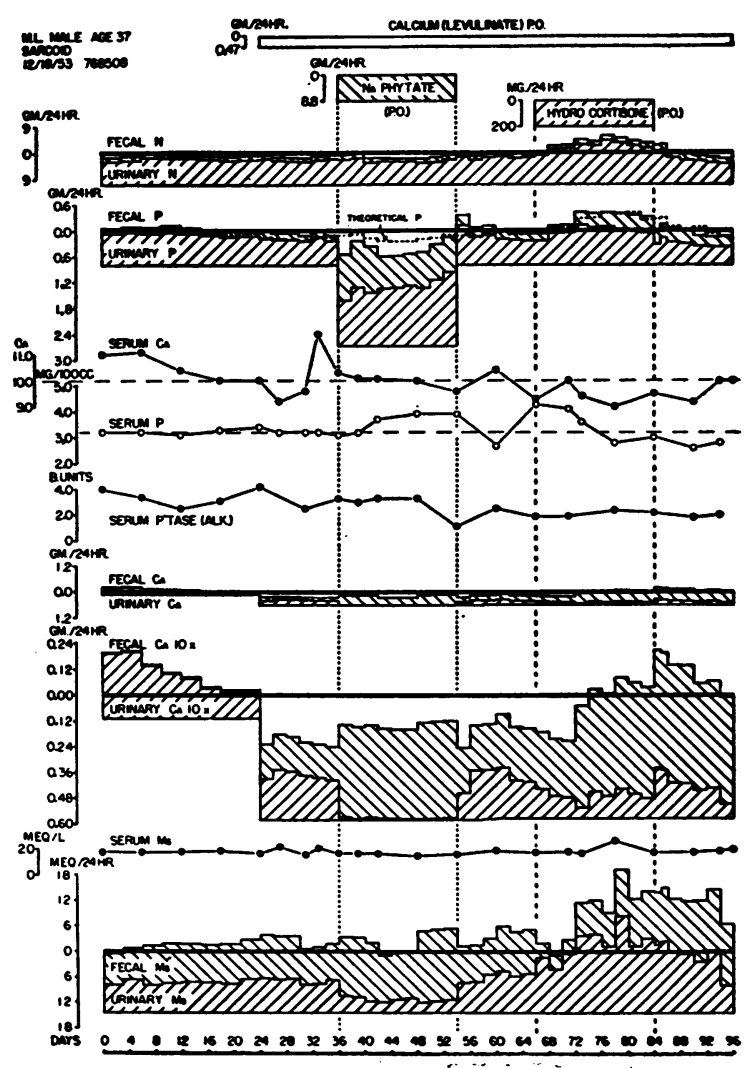

Fig. 8. Study 4, Nitrogen, Phosphorus, Calcium and Magnesium Balance Data during Low and Medium Calcium Intakes, Sodium Phytate and HydroCORTISONe Therapy of M. L., a 37-Year-Old Man with SARCOID

The very high urinary calcium at the beginning of the study probably reflects a higher calcium intake prior to this study.

Patient M. L. was in nitrogen balance except for a period of negative nitrogen balance while on hydrocortisone. He was in slightly negative phosphorus balance during the low calcium intake fore-control, in slightly positive phosphorus balance on the higher calcium intake forecontrol, in positive phosphorus balance on sodium phytate and in negative phosphorus balance on hydrocortisone. Fecal phosphorus was extremely low during the control periods and increased when the fecal calcium increased during sodium phytate and hydrocortisone administration. 
Study 4. Patient M. L. (Figures 8, 9, 10 and Table III)

This 96-day complete balance study consists of 24 days on a low calcium intake (120 mg.), 12 days on a higher calcium intake (590 mg.) which was then continued for the rest of the study, 18 days on sodium phytate powder $8.8 \mathrm{Gm}$. per day, 12 days off medication, 18 days on $200 \mathrm{mg}$. hydrocortisone daily in divided doses, and 12 days aftercontrol.

The serum calcium values were too variable for interpretation. Sodium phytate raised the serum phosphorus slightly. The serum alkaline phosphatase was normal throughout the study.

Fecal calcium averaged $8 \mathrm{mg}$. per day during the low calcium (120 mg. per day) fore-control during which time the urinary calcium decreased from 350 to $130 \mathrm{mg}$. per day. The patient achieved calcium equilibrium at the end of the

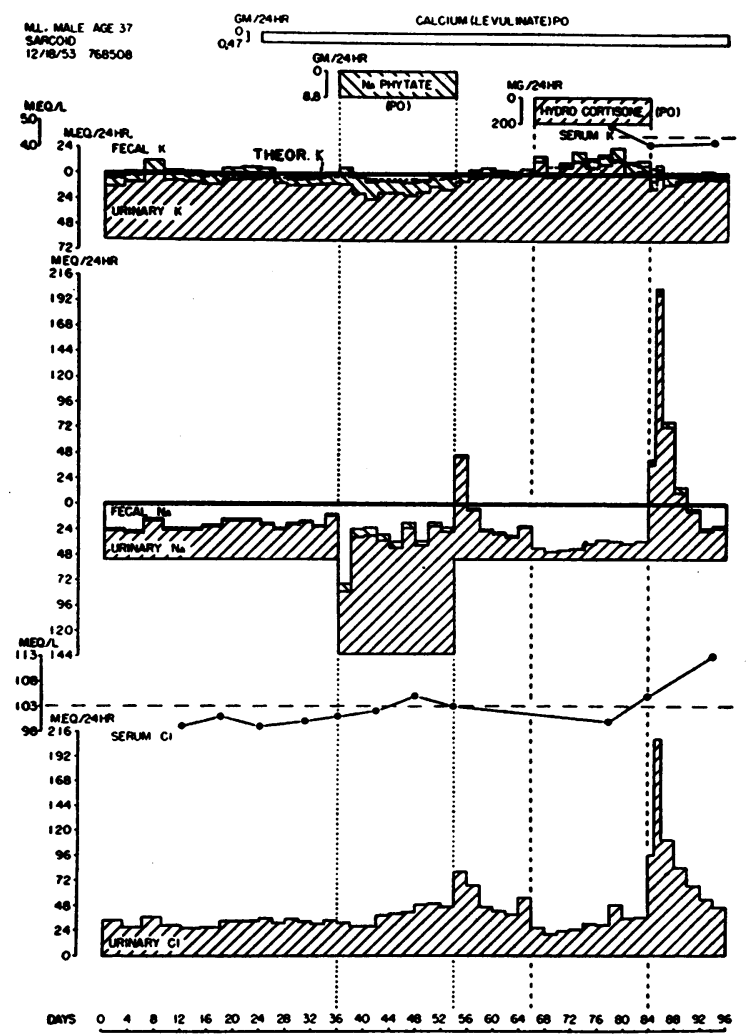

Fig. 9. Potassium, Sodium and Chloride Balance Data DURing Study 4

Urinary potassium excretion increased abruptly the first two days on hydrocortisone; the urinary potassium : nitrogen ratio during these two days was greater than the normal protoplasmic ratio of these substances. (See Table III.)

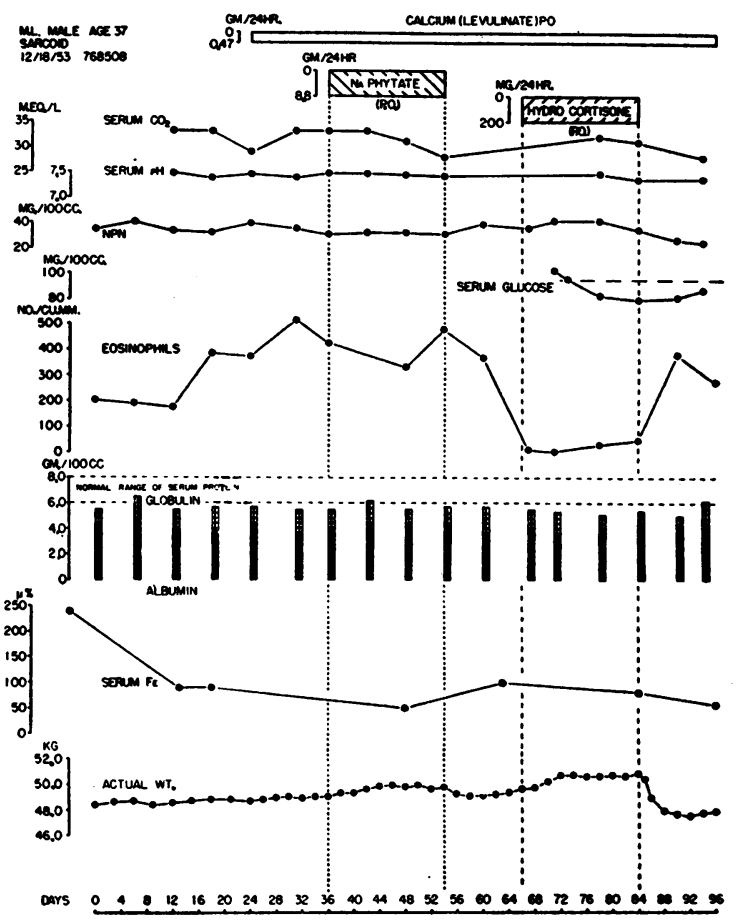

Fig. 10. Other Data of Study 4

The serum $\mathrm{CO}_{2}, \mathrm{pH}, \mathrm{NPN}$ and proteins were essentially constant throughout the study. The initial high serum iron value was not confirmed by other determinations during the fore-control.

low calcium fore-control and was in about $200 \mathrm{mg}$. positive calcium balance on the higher calcium intake, except during and immediately following hydrocortisone administration.

Sodium phytate markedly increased the fecal phosphorus and the urinary phosphorus excretions. Note that during sodium phytate administration the decrease of urinary calcium (to an average value of $6 \mathrm{mg}$. per day!) and of magnesium are of the same magnitude as the increases in fecal calcium and magnesium. Calcium and phosphorus balances recovered rapidly when sodium phytate was discontinued.

Hydrocortisone increased fecal calcium and slightly decreased urinary calcium excretion. Fecal phosphorus and urinary phosphorus also increased during hydrocortisone and decreased during the brief after-control. The "theoretical" phosphorus balance during hydrocortisone therapy agreed with the "actual" phosphorus balance.

\section{SUM MARY OF CALCIUM BALANCES}

In Figure 11 are summarized the average calcium balances of the control periods of these 3 


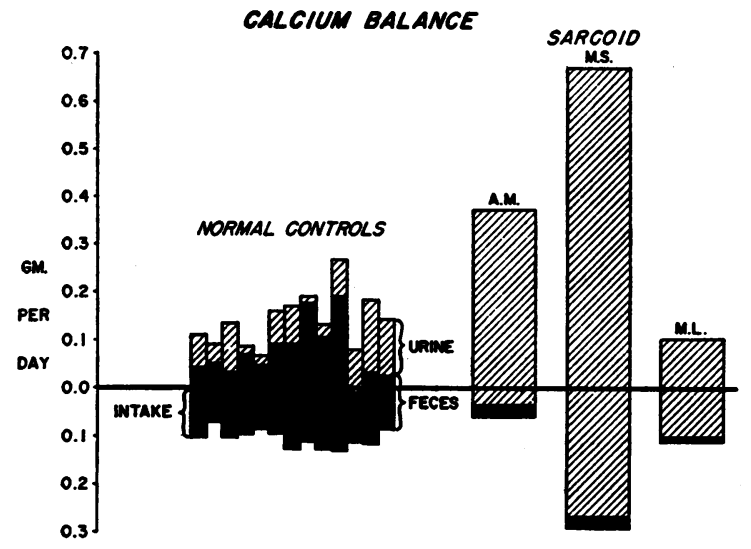

Fig. 11. Summary of the Calcium Balance Data of Three Patients with Sarcoid in Contrast to the Calcium Balance of 13 Normal Subjects on a Low Calcium Intake

Each column represents the average of one or more six-day collection period.

patients with sarcoid as contrasted with the values for 13 normal controls (17). All these studies were performed on very low and roughly comparable calcium intakes. In each of the patients with sarcoid the fecal calcium was markedly less than normal. In studies 1 and 2 the urinary calcium was greater than could be accounted for by the intake, even with the addition of the $200 \mathrm{mg}$. per day which normally is excreted in the feces even on very low calcium intakes.

The calcium balance was more closely related to calcium intake in these patients with sarcoid than it is normally.

Cortisone and hydrocortisone increased the fecal calcium and decreased the urinary calcium in studies No. 2 and No. 4 . In study No. 3 cortisone normalized the fecal calcium excretion without normalizing the urinary calcium.

Sodium phytate increased the fecal calcium and decreased the urinary calcium. In study No. 3 sodium phytate decreased urinary calcium without markedly altering the already normal fecal calcium excretion.

\section{INTERPRETATION OF THE CALCIUM BALANCE IN SARCOID}

The abnormalities of calcium metabolism in these 3 patients with sarcoid are remarkably similar to and suggestive of hypervitaminosis $\mathrm{D}$.

$A$. Evidence for the first action of vitamin $D-$ increased calcium absorption from the intestine. As shown in Figure 11 all three patients had lower than normal fecal calcium excretions at low levels of calcium intake. Increased calcium absorption would explain this and the clinical observation that most patients with sarcoid do not develop demineralization of the bones despite long-continued hypercalcuria.

Increased calcium absorption has been noted with vitamin $\mathrm{D}$ and dihydrotachysterol administration (18) and may be present to some degree in patients with hyperparathyroidism and idiopathic hypercalcuria (19). Although Albright, Bauer, Ropes, and Aub (20) concluded that administered parathyroid hormone was without effect on the fecal calcium yet their studies $(21,22)$ reveal that patients with hyperparathyroidism may have extremely low fecal calcium values. It may be argued that the low serum phosphorus of hyperparathyroidism favors increased absorption of calcium and phosphorus from the intestine even as it may favor increased resorption of calcium and phosphorus from bone. Against this is a study (22) in which the fecal calcium excretion was slightly less rather than more when the serum phosphorus was raised to normal by means of a huge phosphorus intake in a patient with hyperparathyroidism.

Note that the hypercalcemia and hypercalcuria which might result from increased absorption in sarcoid would be dependent upon and limited in degree by the calcium intake.

TABLE II

Fecal nitrogen, sodium, and potassium values in patients M. S. and M. L.

\begin{tabular}{|c|c|c|c|c|}
\hline \multirow[b]{2}{*}{ Patient } & \multirow[b]{2}{*}{ Substance } & \multirow[b]{2}{*}{ Average control value } & \multicolumn{2}{|c|}{ Normal values (24) } \\
\hline & & & Average & Range \\
\hline $\begin{array}{l}\text { M. S. } \\
\text { M. L. }\end{array}$ & $\begin{array}{l}\text { nitrogen } \\
\text { sodium } \\
\text { potassium } \\
\text { sodium }\end{array}$ & $\begin{array}{l}0.78 \mathrm{gm} . / \text { day } \\
0.24 \mathrm{mEq} \cdot / \text { day }(0.2 \% \text { Intake) } \\
6.33 \mathrm{mEq} \cdot / \text { day (8 \% Intake) } \\
0.82 \mathrm{mEq} \cdot / \text { day (1.6\% Intake) }\end{array}$ & $\begin{array}{l}1.283 \\
3.1 \\
9.0 \\
3.1\end{array}$ & $\begin{array}{l}(0.43-2.30) \\
(0.35-7.68) \\
(2.94-17.13) \\
(0.35-7.68)\end{array}$ \\
\hline
\end{tabular}


$B$. Evidence for the second action of vitamin $D$-the parathyroid-hormone-like action. In studies No. 1 and No. 3, and initially in study No. 4, the urinary calcium excretion was greater than the calcium intake, a phenomenon unaccounted for by increased calcium absorption alone. The administration of large doses of vitamin $\mathrm{D}$ to patients with hypoparathyroidism (18) may increase the urinary phosphorus excretion, decrease the serum phosphorus, raise the serum calcium, and finally raise the urinary calcium to levels greater than the intake. This sequence of events has been epitomized as the parathyroid-hormone-like action of vitamin D (18). The hypercalcemia and hypercalcuria which result from this action of vitamin $\mathrm{D}$ are dependent upon bone as a source for calcium and are not limited in degree by the level of calcium intake.

When parathyroid hormone is administered the "actual phosphorus excretion" initially is greater than the "theoretical phosphorus excretion" (vide supra); the reverse is true when parathyroid hormone is discontinued (20). If the second action of vitamin $\mathrm{D}$ were present in these patients and were corrected by cortisone one might expect the actual phosphorus excretion to fall below

TABLE III

Complete balance study data for M. L., study 4 (each period is six days)

\begin{tabular}{|c|c|c|c|c|c|c|c|c|c|c|c|c|}
\hline \multirow[b]{2}{*}{ Period } & \multicolumn{4}{|c|}{ Calcium $m g . / 24^{\circ}$} & \multicolumn{4}{|c|}{ Phosphorus mg. $/ 24^{\circ}$} & \multicolumn{4}{|c|}{ Nitrogen $\mathrm{Gm} . / 24^{\circ}$} \\
\hline & Urine & Feces & Intake & Balance & Urine & Feces & Intake & Balance & Urine & Feces & Intake & Balance \\
\hline $\begin{array}{c}1 \mathrm{~A} \\
1 \mathrm{~B} \\
2 \mathrm{~A} \\
2 \mathrm{~B} \\
3 \mathrm{~A} \\
3 \mathrm{~B} \\
4 \mathrm{~A} \\
4 \mathrm{~B} \\
5 \mathrm{~A} \\
5 \mathrm{~B} \\
5 \mathrm{C} \\
6 \mathrm{~A} \\
6 \mathrm{~B} \\
6 \mathrm{C} \\
7 \mathrm{~A} \\
7 \mathrm{~B} \\
7 \mathrm{C} \\
8 \mathrm{~A} \\
8 \mathrm{~B} \\
8 \mathrm{C} \\
9 \mathrm{~A} \\
9 \mathrm{~B} \\
9 \mathrm{C} \\
10 \mathrm{~A} \\
10 \mathrm{~B} \\
10 \mathrm{C} \\
11 \mathrm{~A} \\
11 \mathrm{~B} \\
11 \mathrm{C} \\
12 \mathrm{~A} \\
12 \mathrm{~B} \\
12 \mathrm{C} \\
13 \mathrm{~A} \\
13 \mathrm{~B} \\
13 \mathrm{C} \\
14 \mathrm{~A} \\
14 \mathrm{~B} \\
14 \mathrm{C} \\
15 \mathrm{~A} \\
15 \mathrm{~B} \\
15 \mathrm{C} \\
15 \mathrm{D} \\
16 \mathrm{~A} \\
16 \mathrm{~B} \\
16 \mathrm{C}\end{array}$ & $\begin{array}{r}301 \\
310 \\
244 \\
207 \\
185 \\
137 \\
120 \\
120 \\
193 \\
237 \\
226 \\
208 \\
198 \\
185 \\
12 \\
4 \\
10 \\
5 \\
2 \\
2 \\
2 \\
5 \\
8 \\
125 \\
231 \\
231 \\
238 \\
176 \\
171 \\
137 \\
105 \\
97 \\
48 \\
127 \\
104 \\
139 \\
115 \\
95 \\
235 \\
224 \\
166 \\
164 \\
132 \\
142 \\
68\end{array}$ & $\begin{array}{r}6 \\
6 \\
8 \\
8 \\
10 \\
10 \\
12 \\
12 \\
160 \\
160 \\
160 \\
155 \\
155 \\
155 \\
431 \\
431 \\
431 \\
320 \\
320 \\
320 \\
453 \\
453 \\
453 \\
211 \\
211 \\
211 \\
249 \\
249 \\
249 \\
264 \\
264 \\
264 \\
475 \\
475 \\
475 \\
516 \\
516 \\
516 \\
549 \\
549 \\
549 \\
549 \\
496 \\
496 \\
496\end{array}$ & $\begin{array}{l}\mathbf{1 1 0} \\
110 \\
110 \\
110 \\
110 \\
110 \\
110 \\
110 \\
\mathbf{5 8 2} \\
\mathbf{5 8 2} \\
\mathbf{5 8 2} \\
\mathbf{5 8 2} \\
\mathbf{5 8 2} \\
\mathbf{5 8 2} \\
\mathbf{5 8 2} \\
\mathbf{5 8 2} \\
\mathbf{5 8 2} \\
\mathbf{5 8 2} \\
\mathbf{5 8 2} \\
\mathbf{5 8 2} \\
\mathbf{5 8 2} \\
\mathbf{5 8 2} \\
\mathbf{5 8 2} \\
\mathbf{5 8 2} \\
\mathbf{5 8 2} \\
\mathbf{5 7 8} \\
\mathbf{5 7 4} \\
\mathbf{5 7 4} \\
\mathbf{5 7 4} \\
\mathbf{5 7 4} \\
\mathbf{5 7 4} \\
\mathbf{5 7 4} \\
\mathbf{5 7 4} \\
\mathbf{5 7 4} \\
\mathbf{5 7 4} \\
\mathbf{5 7 4} \\
\mathbf{5 7 4} \\
\mathbf{5 7 4} \\
\mathbf{5 7 4} \\
\mathbf{5 7 4} \\
\mathbf{5 7 4} \\
\mathbf{5 7 4} \\
\mathbf{5 7 4} \\
\mathbf{5 7 4} \\
\mathbf{5 7 4}\end{array}$ & $\begin{array}{r}-197 \\
-206 \\
-142 \\
-105 \\
-85 \\
-37 \\
-22 \\
-22 \\
+229 \\
+185 \\
+196 \\
+219 \\
+229 \\
+242 \\
+139 \\
+147 \\
+141 \\
+257 \\
+260 \\
+260 \\
+127 \\
+124 \\
+121 \\
+246 \\
+140 \\
+136 \\
+87 \\
+149 \\
+154 \\
+173 \\
+205 \\
+213 \\
+51 \\
+28 \\
+\quad 5 \\
-81 \\
-57 \\
-37 \\
-210 \\
-199 \\
+141 \\
-139 \\
-54 \\
+64 \\
+10\end{array}$ & $\begin{array}{r}\mathbf{7 4 3} \\
\mathbf{7 7 4} \\
\mathbf{7 4 0} \\
\mathbf{7 7 2} \\
\mathbf{7 3 0} \\
\mathbf{6 8 7} \\
\mathbf{6 4 9} \\
\mathbf{6 6 8} \\
\mathbf{6 2 0} \\
\mathbf{5 8 6} \\
\mathbf{5 9 3} \\
\mathbf{5 4 9} \\
\mathbf{6 5 4} \\
\mathbf{5 6 1} \\
1, \mathbf{0 4 3} \\
\mathbf{1}, \mathbf{3 6 0} \\
\mathbf{1}, 244 \\
\mathbf{1}, \mathbf{3 1 2} \\
1, \mathbf{3 3 9} \\
1,393 \\
1,342 \\
1, \mathbf{5 3 0} \\
\mathbf{1 , 6 9 7} \\
\mathbf{9 3 4} \\
\mathbf{6 6 0} \\
\mathbf{6 8 5} \\
\mathbf{5 9 9} \\
\mathbf{5 7 7} \\
\mathbf{5 4 7} \\
\mathbf{5 4 9} \\
\mathbf{7 3 4} \\
\mathbf{7 4 1} \\
\mathbf{9 0 9} \\
\mathbf{8 8 4} \\
\mathbf{8 9 4} \\
\mathbf{8 2 6} \\
\mathbf{7 8 9} \\
\mathbf{7 4 6} \\
\mathbf{4 7 5} \\
\mathbf{6 4 0} \\
\mathbf{5 3 0} \\
\mathbf{4 8 5} \\
\mathbf{4 3 2} \\
\mathbf{4 1 9} \\
\mathbf{4 2 3}\end{array}$ & $\begin{array}{r}112 \\
112 \\
139 \\
139 \\
127 \\
127 \\
143 \\
143 \\
158 \\
158 \\
158 \\
131 \\
131 \\
131 \\
1,064 \\
1,064 \\
1,064 \\
747 \\
747 \\
747 \\
821 \\
821 \\
821 \\
218 \\
218 \\
218 \\
174 \\
174 \\
174 \\
176 \\
176 \\
176 \\
309 \\
309 \\
309 \\
363 \\
363 \\
363 \\
307 \\
307 \\
307 \\
307 \\
235 \\
235 \\
235\end{array}$ & $\begin{array}{r}800 \\
800 \\
800 \\
800 \\
800 \\
800 \\
800 \\
800 \\
800 \\
800 \\
800 \\
800 \\
800 \\
800 \\
2,666 \\
2,666 \\
2,666 \\
2,666 \\
2,666 \\
2,666 \\
2,666 \\
2,666 \\
2,666 \\
800 \\
800 \\
800 \\
800 \\
800 \\
800 \\
800 \\
800 \\
800 \\
800 \\
800 \\
800 \\
800 \\
800 \\
800 \\
800 \\
800 \\
800 \\
800 \\
800 \\
800 \\
800\end{array}$ & $\begin{array}{l}-55 \\
-86 \\
-79 \\
-111 \\
-57 \\
-14 \\
+\quad 8 \\
+\quad 11 \\
+22 \\
+56 \\
+49 \\
+120 \\
+15 \\
+108 \\
+559 \\
+242 \\
+358 \\
+607 \\
+580 \\
+526 \\
+503 \\
+315 \\
+148 \\
+352 \\
-78 \\
-103 \\
+27 \\
+49 \\
+79 \\
+75 \\
+110 \\
-117 \\
-418 \\
-393 \\
-403 \\
-389 \\
-352 \\
-309 \\
+18 \\
-147 \\
+37 \\
+\quad 8 \\
+133 \\
+146 \\
+142\end{array}$ & $\begin{array}{r}7.92 \\
8.44 \\
9.42 \\
9.08 \\
9.15 \\
8.67 \\
8.05 \\
8.45 \\
8.82 \\
8.30 \\
7.93 \\
7.81 \\
8.40 \\
8.84 \\
8.62 \\
8.99 \\
7.53 \\
7.92 \\
7.76 \\
7.77 \\
7.33 \\
7.72 \\
8.75 \\
9.58 \\
8.49 \\
9.43 \\
9.66 \\
9.10 \\
9.43 \\
10.09 \\
12.19 \\
12.37 \\
13.77 \\
13.41 \\
15.24 \\
14.33 \\
13.32 \\
12.58 \\
11.37 \\
11.72 \\
9.27 \\
8.30 \\
8.08 \\
7.48 \\
6.99\end{array}$ & $\begin{array}{l}1.43 \\
1.43 \\
1.50 \\
1.50 \\
1.31 \\
1.31 \\
1.48 \\
1.48 \\
1.38 \\
1.38 \\
1.38 \\
1.33 \\
1.33 \\
1.33 \\
1.72 \\
1.72 \\
1.72 \\
1.31 \\
1.31 \\
1.31 \\
1.63 \\
1.63 \\
1.63 \\
1.31 \\
1.31 \\
1.31 \\
1.67 \\
1.67 \\
1.67 \\
1.22 \\
1.22 \\
1.22 \\
1.64 \\
1.64 \\
1.64 \\
1.79 \\
1.79 \\
1.79 \\
2.16 \\
2.16 \\
2.16 \\
2.16 \\
1.87 \\
1.87 \\
1.87\end{array}$ & $\begin{array}{l}11.03 \\
11.03 \\
11.03 \\
11.03 \\
11.03 \\
11.03 \\
11.03 \\
11.03 \\
11.03 \\
11.03 \\
11.03 \\
11.03 \\
11.03 \\
11.03 \\
11.03 \\
11.03 \\
11.03 \\
11.03 \\
11.03 \\
11.03 \\
11.03 \\
11.03 \\
11.03 \\
11.03 \\
11.03 \\
11.03 \\
11.03 \\
11.03 \\
11.03 \\
11.03 \\
11.03 \\
11.03 \\
11.03 \\
11.03 \\
11.03 \\
11.03 \\
11.03 \\
11.03 \\
11.03 \\
11.03 \\
11.03 \\
11.03 \\
11.03 \\
11.03 \\
11.03\end{array}$ & $\begin{array}{l}+1.68 \\
+1.16 \\
+0.11 \\
+0.45 \\
+0.57 \\
+1.05 \\
+1.50 \\
+1.10 \\
+0.83 \\
+1.35 \\
+1.72 \\
+1.89 \\
+1.30 \\
+0.86 \\
+0.69 \\
+0.32 \\
+1.78 \\
+1.80 \\
+1.96 \\
+1.95 \\
+2.07 \\
+1.68 \\
+0.65 \\
+0.14 \\
+1.23 \\
+0.29 \\
+0.30 \\
+0.26 \\
-0.07 \\
-0.28 \\
-2.38 \\
-2.56 \\
-4.38 \\
-4.02 \\
-5.85 \\
-5.09 \\
-4.08 \\
-3.34 \\
-2.50 \\
-2.85 \\
-0.40 \\
+0.57 \\
+1.08 \\
+1.68 \\
+2.17\end{array}$ \\
\hline
\end{tabular}


CAUSE OF HYPERCALCURIA IN SARCOIDOSIS

TABLE III-Continued

\begin{tabular}{|c|c|c|c|c|c|c|c|c|c|c|c|c|}
\hline \multicolumn{4}{|c|}{ Potassium $m E q . / 24^{\circ}$} & \multicolumn{4}{|c|}{ Sodium $m E q . / 24^{\circ}$} & \multicolumn{4}{|c|}{ Magnesium $m E q . / 24^{\circ}$} & \multirow{2}{*}{$\begin{array}{c}\text { Urine } \\
\text { chloride } \\
m E q . / 24^{\circ}\end{array}$} \\
\hline Urine & Feces & Intake & Balance & Urine & Feces & Intake & Balance & Urine & Feces & Intake & Balance & \\
\hline $\begin{array}{l}49.78 \\
55.32 \\
64.02 \\
55.46 \\
54.65 \\
52.98 \\
56.80 \\
58.19 \\
58.80 \\
54.26 \\
51.88 \\
51.61 \\
53.32 \\
54.48 \\
53.30 \\
44.33 \\
39.33 \\
45.15 \\
44.56 \\
43.28 \\
45.76 \\
50.62 \\
48.28 \\
56.45 \\
61.01 \\
63.58 \\
61.46 \\
60.22 \\
62.28 \\
75.03 \\
60.10 \\
68.65 \\
75.43 \\
70.14 \\
73.23 \\
77.22 \\
64.31 \\
65.67 \\
48.78 \\
60.31 \\
52.85 \\
57.27 \\
58.32 \\
59.67 \\
57.87\end{array}$ & $\begin{array}{r}9.00 \\
9.00 \\
9.87 \\
9.87 \\
8.50 \\
8.50 \\
10.10 \\
10.10 \\
8.50 \\
8.50 \\
8.50 \\
8.35 \\
8.35 \\
8.35 \\
15.30 \\
15.30 \\
15.30 \\
10.83 \\
10.83 \\
10.83 \\
10.57 \\
10.57 \\
10.57 \\
5.00 \\
5.00 \\
5.00 \\
5.27 \\
5.27 \\
5.27 \\
4.47 \\
4.47 \\
4.47 \\
8.18 \\
8.18 \\
8.18 \\
9.85 \\
9.85 \\
9.85 \\
7.17 \\
7.17 \\
7.17 \\
7.17 \\
6.03 \\
6.03 \\
6.03\end{array}$ & $\begin{array}{l}62.40 \\
62.40 \\
62.40 \\
62.40 \\
62.40 \\
62.40 \\
62.40 \\
62.40 \\
62.40 \\
62.40 \\
62.40 \\
62.40 \\
62.40 \\
62.40 \\
62.40 \\
62.40 \\
62.40 \\
62.40 \\
62.40 \\
62.40 \\
62.40 \\
62.40 \\
62.40 \\
62.40 \\
62.40 \\
62.40 \\
62.40 \\
62.40 \\
62.40 \\
62.40 \\
62.40 \\
62.40 \\
62.40 \\
62.40 \\
62.40 \\
62.40 \\
62.40 \\
62.40 \\
62.40 \\
62.40 \\
62.40 \\
62.40 \\
62.40 \\
62.40 \\
62.40\end{array}$ & $\begin{array}{l}+3.62 \\
+1.92 \\
-11.49 \\
-2.93 \\
-0.75 \\
+0.92 \\
-4.50 \\
-5.89 \\
-4.90 \\
-0.36 \\
+2.02 \\
+2.44 \\
+0.73 \\
-0.43 \\
-6.20 \\
+2.77 \\
+7.77 \\
+6.42 \\
+7.01 \\
+8.29 \\
+6.07 \\
+1.21 \\
+3.55 \\
+0.95 \\
-3.61 \\
-6.18 \\
-4.33 \\
-3.09 \\
-5.15 \\
-17.10 \\
-2.17 \\
-10.72 \\
-21.21 \\
-15.92 \\
-19.01 \\
-24.67 \\
-11.76 \\
-13.12 \\
+6.45 \\
+5.08 \\
+2.38 \\
-2.04 \\
-1.95 \\
-3.30 \\
-1.50\end{array}$ & $\begin{array}{r}26.78 \\
25.45 \\
36.84 \\
27.80 \\
27.99 \\
30.88 \\
36.72 \\
36.66 \\
32.91 \\
28.45 \\
32.69 \\
35.39 \\
31.46 \\
41.85 \\
59.74 \\
111.62 \\
113.36 \\
109.40 \\
102.00 \\
119.85 \\
103.92 \\
121.86 \\
117.38 \\
97.52 \\
47.27 \\
27.66 \\
25.02 \\
20.76 \\
29.58 \\
9.62 \\
6.59 \\
8.37 \\
10.30 \\
13.41 \\
17.76 \\
17.28 \\
15.23 \\
17.44 \\
89.01 \\
251.05 \\
125.96 \\
63.14 \\
44.83 \\
28.23 \\
28.60\end{array}$ & $\begin{array}{l}0.95 \\
0.95 \\
0.85 \\
0.85 \\
0.94 \\
0.94 \\
0.50 \\
0.50 \\
0.55 \\
0.55 \\
0.55 \\
1.15 \\
1.15 \\
1.15 \\
5.90 \\
5.90 \\
5.90 \\
3.63 \\
3.63 \\
3.63 \\
2.47 \\
2.47 \\
2.47 \\
0.60 \\
0.60 \\
0.60 \\
0.80 \\
0.80 \\
0.80 \\
0.91 \\
0.91 \\
0.91 \\
1.87 \\
1.87 \\
1.87 \\
2.20 \\
2.20 \\
2.20 \\
4.63 \\
4.63 \\
4.63 \\
4.63 \\
2.13 \\
2.13 \\
2.13\end{array}$ & $\begin{array}{r}\mathbf{5 2 . 1 0} \\
\mathbf{5 2 . 1 0} \\
\mathbf{5 2 . 1 0} \\
\mathbf{5 2 . 1 0} \\
\mathbf{5 2 . 1 0} \\
\mathbf{5 2 . 1 0} \\
\mathbf{5 2 . 1 0} \\
\mathbf{5 2 . 1 0} \\
\mathbf{5 2 . 1 0} \\
\mathbf{5 2 . 1 0} \\
\mathbf{5 2 . 1 0} \\
\mathbf{5 2 . 1 0} \\
\mathbf{5 2 . 1 0} \\
\mathbf{5 2 . 1 0} \\
\mathbf{1 4 1 . 8 4} \\
\mathbf{1 4 1 . 8 4} \\
\mathbf{1 4 1 . 8 4} \\
\mathbf{1 4 1 . 8 4} \\
\mathbf{1 4 1 . 8 4} \\
\mathbf{1 4 1 . 8 4} \\
\mathbf{1 4 1 . 8 4} \\
\mathbf{1 4 1 . 8 4} \\
\mathbf{1 4 1 . 8 4} \\
\mathbf{5 2 . 1 0} \\
\mathbf{5 2 . 1 0} \\
\mathbf{5 2 . 1 0} \\
\mathbf{5 2 . 1 0} \\
\mathbf{5 2 . 1 0} \\
\mathbf{5 2 . 1 0} \\
\mathbf{5 2 . 1 0} \\
\mathbf{5 2 . 1 0} \\
\mathbf{5 2 . 1 0} \\
\mathbf{5 2 . 1 0} \\
\mathbf{5 2 . 1 0} \\
\mathbf{5 2 . 1 0} \\
\mathbf{5 2 . 1 0} \\
\mathbf{5 2 . 1 0} \\
\mathbf{5 2 . 1 0} \\
\mathbf{5 2 . 1 0} \\
\mathbf{5 2 . 1 0} \\
\mathbf{5 2 . 1 0} \\
\mathbf{5 2 . 1 0} \\
\mathbf{5 2 . 1 0} \\
\mathbf{5 2 . 1 0} \\
\mathbf{5 2 . 1 0}\end{array}$ & $\begin{array}{rr}+ & 24.37 \\
+ & 25.70 \\
+ & 14.41 \\
+ & 23.45 \\
+ & 23.17 \\
+ & 20.28 \\
+ & 14.88 \\
+ & 14.94 \\
+ & 18.64 \\
+ & 23.10 \\
+ & 18.86 \\
+ & 15.56 \\
+ & 19.49 \\
+ & 9.10 \\
+ & 76.20 \\
+ & 24.32 \\
+ & 22.58 \\
+ & 28.81 \\
+ & 36.21 \\
+ & 18.36 \\
+ & 35.45 \\
+ & 17.51 \\
+ & 21.99 \\
& 46.02 \\
+ & 4.23 \\
+ & 23.84 \\
+ & 26.28 \\
+ & 30.54 \\
+ & 21.72 \\
+ & 41.57 \\
+ & 44.60 \\
+ & 42.82 \\
+ & 39.93 \\
+ & 36.82 \\
+ & 32.47 \\
+ & 32.62 \\
+ & 34.67 \\
+ & 32.46 \\
- & 41.54 \\
-203.58 \\
+ & 78.49 \\
+ & 15.67 \\
+ & 5.14 \\
+ & 21.74 \\
+ & 21.37\end{array}$ & $\begin{array}{r}6.39 \\
7.74 \\
6.30 \\
6.77 \\
7.05 \\
6.90 \\
6.65 \\
7.67 \\
8.01 \\
7.62 \\
7.76 \\
6.43 \\
6.72 \\
7.48 \\
3.77 \\
3.60 \\
2.46 \\
2.29 \\
2.94 \\
3.23 \\
2.16 \\
2.53 \\
2.89 \\
6.82 \\
7.14 \\
8.79 \\
9.72 \\
8.40 \\
8.95 \\
12.77 \\
9.97 \\
13.59 \\
17.84 \\
18.21 \\
15.62 \\
22.49 \\
15.62 \\
17.40 \\
15.79 \\
16.83 \\
14.28 \\
13.75 \\
11.94 \\
14.55 \\
6.25\end{array}$ & $\begin{array}{r}7.37 \\
7.37 \\
9.37 \\
9.37 \\
8.94 \\
8.94 \\
9.31 \\
9.31 \\
10.10 \\
10.10 \\
10.10 \\
8.52 \\
8.52 \\
8.52 \\
13.89 \\
13.89 \\
13.89 \\
11.04 \\
11.04 \\
11.04 \\
16.91 \\
16.91 \\
16.91 \\
8.66 \\
8.66 \\
8.66 \\
10.44 \\
10.44 \\
10.44 \\
3.40 \\
3.40 \\
3.40 \\
7.73 \\
7.73 \\
7.73 \\
11.04 \\
11.04 \\
11.04 \\
12.37 \\
12.37 \\
12.37 \\
12.37 \\
10.41 \\
10.41 \\
10.41\end{array}$ & $\begin{array}{l}14.32 \\
14.32 \\
14.32 \\
14.32 \\
14.32 \\
14.32 \\
14.32 \\
14.32 \\
14.32 \\
14.32 \\
14.32 \\
14.32 \\
14.32 \\
14.32 \\
14.32 \\
14.32 \\
14.32 \\
14.32 \\
14.32 \\
14.32 \\
14.32 \\
14.32 \\
14.32 \\
14.32 \\
14.32 \\
14.32 \\
14.32 \\
14.32 \\
14.32 \\
14.32 \\
14.32 \\
14.32 \\
14.32 \\
14.32 \\
14.32 \\
14.32 \\
14.32 \\
14.32 \\
14.32 \\
14.32 \\
14.32 \\
14.32 \\
14.32 \\
14.32 \\
14.32\end{array}$ & 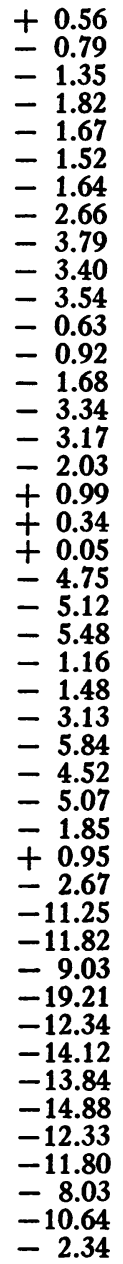 & $\begin{array}{r}34.31 \\
26.90 \\
36.64 \\
28.92 \\
26.33 \\
27.13 \\
33.19 \\
33.00 \\
35.10 \\
30.88 \\
34.62 \\
31.90 \\
29.80 \\
33.70 \\
30.82 \\
27.64 \\
28.00 \\
37.67 \\
40.18 \\
40.66 \\
47.61 \\
48.71 \\
46.03 \\
79.74 \\
67.10 \\
45.98 \\
42.35 \\
39.00 \\
54.84 \\
25.55 \\
19.55 \\
23.26 \\
24.32 \\
29.82 \\
29.39 \\
48.00 \\
34.84 \\
36.46 \\
96.09 \\
208.78 \\
110.94 \\
84.23 \\
66.74 \\
53.87 \\
46.46\end{array}$ \\
\hline
\end{tabular}

the "theoretical" phosphorus excretion when cortisone or hydrocortisone therapy was begun. In fact the "theoretical phosphorus balance," as indicated by the dotted lines on the phosphorus balances in Figures 1 and 8, agrees well with the "actual phosphorus balance." It has been noted in other studies (23) that cortisone and hydrocortisone may increase the actual phosphorus excretion above the "theoretical" phosphorus excretion initially, an effect opposite to the one anticipated in this study and one which might explain the failure of the "theoretical" phosphorus to deviate from the actual phosphorus balance in these studies. A parallel phenomenon, potassium diu- resis in excess of that predicted from the nitrogen balance, was observed at the start of cortisone and hydrocortisone therapy in studies No. 2 and No. 4.

In the second study on patient M. S., fecal calcium was greater than the intake which suggests that this dose of cortisone had corrected the first action of vitamin D. However, the urinary calcium remained high, showing that the two suspected actions of vitamin $\mathrm{D}$, if present in these patients, are separable and not necessarily related. It is suggested that sodium phytate decreased the urinary calcium in study No. 3 , not by decreasing calcium absorption, but by supplying the inorganic phosphorus for the phosphorus-diuretic activity 
present, thus sparing the bones from increased resorption and thereby decreasing the serum calcium.

C. Evidence for a third action of vitamin $D-$ increased absorption of nitrogen, sodium, potassium, magnesium, and iron. In Table II are summarized some control fecal values of the sarcoid patients as contrasted with normal values.

These fecal values of the sarcoid patients are consistently though not dramatically less than normal.

In Figures 12 and 13 attention is called to the lower values noted for fecal nitrogen, magnesium, sodium, and potassium at the beginning of the study (days 0 to 4 ) and at the height of AT-10 (dihydrotachysterol) action (days 36 to 40 ) than those noted in the rest of the study. These examples of increased absorption coincided with

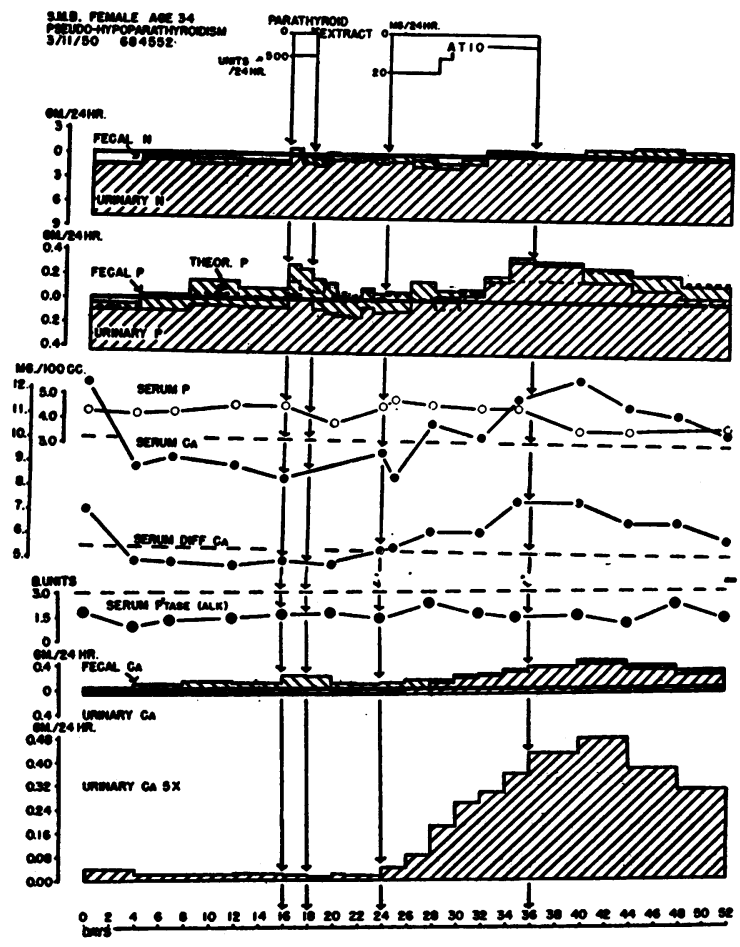

Fig. 12. The Effect of Parathyroid Extract and AT-10 (Dihydrotachysterol) on the Nitrogen, Phosphorus, and Calcium Balances of a Patient with PSEUDOH YPOPARATH YROIDISM

The patient received sufficient AT-10 immediately before and again during this study to cause moderate hypercalcemia.

By the serum diffusible calcium is meant that amount passing a cellophane filter under pressure. These measurements were made by Dr. John Dawson.

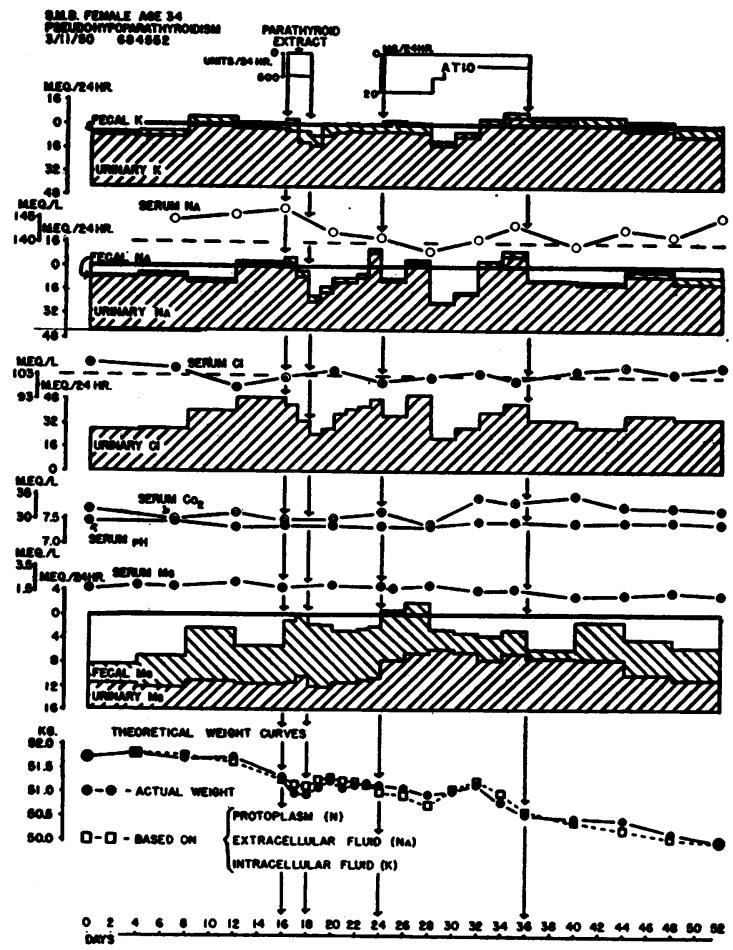

Fig. 13. The Effect of Parathyroid Extract and AT-10 on the Potassium, Sodium and Magnesium Balances and Urinary Chloride of a Patient with PSEUDOH YPOPARATH YROIDISM

Note that minimum fecal values occurred during days 0 to 4 and 36 to 40 and coincided with the episodes of maximum hypercalcemia.

hypercalcemia produced by large doses of AT-10, a vitamin $\mathrm{D}$ congener, just before the study began and again during the study. Vitamin D and AT-10 are closely related compounds and have markedly similar effects in man (25).

Since the initial high serum iron values in patient M. L. could not be demonstrated a second time there is not adequate evidence for increased iron absorption in this condition. It would seem that increased absorption of many substances may occur in sarcoid. It remains for future studies to determine whether iron, a substance normally poorly absorbed, is also better absorbed in sarcoid.

\section{DISCUSSION}

These studies strongly suggest, though they do not prove, that the hypercalcuria of sarcoid is due to endogenous hypervitaminosis D. If this is so, are these patients photosensitive in such a way that their skin forms excessive vitamin $D$ on nor- 
mal actinic exposure? Are they unable to inactivate vitamin $D$ ? Does the sarcoid tissue form a vitamin $\mathrm{D}$-like substance? Is the intestinal flora in sarcoid capable of forming vitamin D-like substances? In favor of the first suggestion is the dry pigmented skin noted generally in M. S. and on the face in patient M. L. Both these patients have recently had recrudescence of hypercalcemia in the summer. In favor of the second suggestion is the observation by Larsson, Liljestrand, and Wahlund (26) of hypercalcemia in 12 of 24 patients with sarcoid treated with 30,000 to 140,000 units vitamin D daily for 6 to 124 days. Nonsarcoid subjects are rarely poisoned with less than 200,000 units administered for months to years. We know of no observations pertinent to the other two possibilities and there are undoubtedly other possible explanations for the changes noted.

The mode of action of ACTH, cortisone and hydrocortisone in sarcoid is obscure. It is known that these drugs may temporarily or permanently cause the disappearance of sarcoid granulomata (27). Since vitamin D and cortisone possess similar structural formulae there may be a direct antagonism between these substances. However, in our experience (24) patients with Cushing's syndrome do not have unusually high fecal calcium excretion nor does cortisone administration increase fecal calcium except in patients with sarcoid.

Dent, Flynn, and Nabarro (28) in 1953 demonstrated correction by cortisone of hypercalcemia and depressed renal function in patients with sarcoid. They concluded that bone destruction was the cause of the hypercalcemia. More recently Anderson, Harper, Dent, and Philpot (29) have concluded that increased calcium absorption is the cause of hypercalcemia in sarcoid. Lack of published standards for normal calcium balance on calcium intakes of 800 to $1,000 \mathrm{mg}$. daily and lack of control data after cortisone administration weaken their evidence for increased calcium absorption in these later studies. It is of interest that most of the instances of increased symptoms due to sarcoid in Dent's patients were reported to occur in the summer months.

\section{SUMMARY AND CONCLUSIONS}

Four complete balance studies on three patients with sarcoid demonstrate the following abnormalities of calcium metabolism:
1. Increased calcium absorption from the intestine.

2. Hypercalcemia.

3. Increased calcium excretion in the urine.

4. Urinary calcium excretion greater than can be accounted for by increased absorption alone.

These changes strongly suggest endogenous vitamin $\mathrm{D}$ intoxication, in which the following sequence of events is observed:

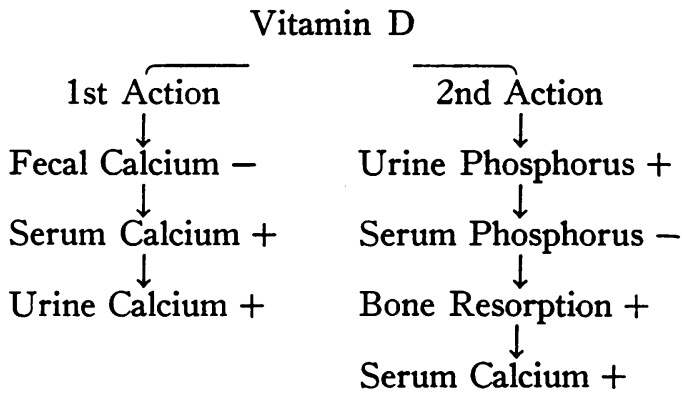

Attention is called to evidence for a possible third action of vitamin D ... the property of increasing intestinal absorption over a wide spectrum of substances. Thus, increased absorption of nitrogen, sodium, potassium and magnesium was noted in one of these studies and in a patient with pseudohypoparathyroidism in whom hypercalcemia was produced by excessive doses of AT-10, a vitamin $\mathrm{D}$ congener.

Cortisone increased the fecal calcium and decreased the urinary calcium excretion of two patients. The mode of action of cortisone in this disease is not known. Sodium phytate also decreased urinary calcium excretion, apparently primarily by increasing fecal calcium excretion.

Sodium phytate appears to be the treatment of choice of the hypercalcuria of sarcoid and its use is suggested for other instances of increased calcium absorption such as vitamin $\mathrm{D}$ poisoning, idiopathic hypercalcuria, and idiopathic hypercalcemia of infants (30).

\section{ACKNOWLEDGMENT}

Balance studies No. 2, No. 3, and No. 4 were carried out with the expert assistance of Miss Eleanor Sullivan, Head Nurse, and Miss Leila Presson, Research Dietician.

\section{REFERENCES}

1. Longcope, W. T., and Freiman, D. G., A study of sarcoidosis based on a combined investigation of 160 cases including 30 autopsies from the Johns 
Hopkins Hospital and Massachusetts General Hospital. Medicine, 1952, 31, 1.

2. Harrell, G. T., and Fisher, S., Blood chemical changes in Boeck's sarcoid with particular reference to protein, calcium and phosphatase values. J. Clin. Invest., $1939,18,687$.

3. Howard, J. E., Personal communication.

4. Schaumann, J., Etude sur le lupus pernio et ses rapports avec les sarcoides et la tuberculose. Ann. de dermat. et syph., 1917, 6, 357.

5. Klatskin, G., and Gordon, M., Renal complications of sarcoidosis and their relationship to hypercalcemia, with a report of two cases simulating hyperparathyroidism. Am. J. Med., 1953, 15, 484.

6. Hardy, H. L., Personal communication.

7. Reifenstein, E. C., Jr., Albright, F., and Wells, S. L., The accumulation, interpretation, and presentation of data pertaining to metabolic balances, notably those of calcium, phosphorus, and nitrogen. J. Clin. Endocrinol., 1945, 5, 367.

8. Berry, J. W., Chappell, D. G., and Barnes, R. B., Improved method of flame photometry. Indust. \& Engin. Chem. (Analyt. Ed.), 1946, 18, 19.

9. Briggs, A. P., Some applications of the colorimetric phosphate method. J. Biol. Chem., 1924, 59, 255.

10. Vestergaard, Per., Rapid micro-modification of the Zimmermann Callow procedure for the determination of 17-ketosteroids in urine. Acta endocrinol., 1951, 8, 193.

11. Albright, F., and Reifenstein, E. C., Jr., The Parathyroid Glands and Metabolic Bone Disease. Baltimore, Md., Williams \& Wilkins Co., 1948, p. 96.

12. Mason, H. L., and Engstrom, W. W., The 17-ketosteroids: Their origin, determination and significance. Physiol. Rev., 1950, 30, 321.

13. Howe, P. E., The use of sodium sulfate as the globulin precipitant in the determination of proteins in blood. J. Biol. Chem., 1921, 49, 93.

14. McCance, R. A., and Widdowson, E. M., Mineral metabolism of healthy adults on white and brown bread dietaries. J. Physiol., 1942, 101, 44.

15. Fiske, C. H., and Subbarow, Y., The colorimetric determination of phosphorus. J. Biol. Chem., 1925, 66, 375.

16. McCance, R. A., and Widdowson, E. M., Phytin in human nutrition. Biochem. J., 1935, 29, 2694.

17. Bauer, W., Albright, F., and Aub, J. C., Studies of calcium and phosphorus metabolism. II. The calcium excretion of normal individuals on a low calcium diet, also data on a case of pregnancy. J. Clin. Invest., 1929, 7, 75.

18. Albright, F., Burnett, C. H., Parson, W., Reifenstein, E. C., Jr., and Roos, A., Osteomalacia and late rickets. The various etiologies met in the United
States with emphasis on that resulting from a specific form of renal acidosis, the therapeutic indications for each etiological sub-group, and the relationship between osteomalacia and Milkman's Syndrome. Medicine, 1946, 25, 399.

19. Albright, F., Henneman, P., Benedict, P. H., and Forbes, A. P., Idiopathic hypercalciuria. (A preliminary report.) Proc. Roy. Soc. Med., 1953, 46, 1077.

20. Albright, F., Bauer, W., Ropes, M., and Aub, J. C., Studies of calcium and phosphorus metabolism. IV. The effect of the parathyroid hormone. J. Clin. Invest., 1929, 7, 139.

21. Bauer, W., Albright, F., and Aub, J. C., A case of osteitis fibrosa cystica (osteomalacia?) with evidence of hyperactivity of the parathyroid bodies. Metabolic study. II. J. Clin. Invest., 1930, 8, 229.

22. Albright, F., Bauer, W., Claflin, D., and Cockrill, J. R., Studies in parathyroid physiology. III. The effect of phosphate ingestion in clinical hyperparathyroidism. J. Clin. Invest., 1932, 11, 411.

23. Bartter, F. C., Fourman, P., Albright, F., Forbes, A. P., Jeffries, W. McK., Griswold, G., Dempsey, E., Bryant, D., and Carroll, E., The effect of adrenocorticotropic hormone in panhypopituitarism. J. Clin. Invest., 1950, 29, 950.

24. Dempsey, E. F., Carroll, E. L., Albright, F., and Henneman, P. H., A study of factors determining fecal electrolyte excretion. To be published.

25. Albright, F., Bloomberg, E., Drake, T., and Sulkowitch, H. W., A comparison of the effects of A. T. 10 (dihydrotachysterol) and vitamin $\mathrm{D}$ on calcium and phosphorus metabolism in hypoparathyroidism. J. Clin. Invest., 1938, 17, 317.

26. Larsson, L. G., Liljestrand, A., and Wahlund, H., Treatment of sarcoidosis with calciferol. Acta med. Scandinav., 1952, 143, 280.

27. Shulman, L. E., Schoenrich, E. H., and Harvey, A. M., The effects of adrenocorticotropic hormone (ACTH) and cortisone on sarcoidosis. Bull. Johns Hopkins Hosp., 1952, 91, 371.

28. Dent, C. E., Flynn, F. V., and Nabarro, J. D. N., Hypercalcemia and impairment of renal function in generalized sarcoidosis. Brit. M. J., 1953, 2, 808.

29. Anderson, J., Harper, C., Dent, C. E., and Philpot, G. R., Effect of cortisone on calcium metabolism in sarcoidosis with hypercalcemia. Possible antagonistic actions of cortisone and vitamin D. Lancet, 1954, 2, 720.

30. Lightwood, R., Idiopathic hypercalcemia with failure to thrive: nephrocalcinosis. Proc. Roy. Soc. Med., 1952, 45, 401. 